\title{
Psychosocial outcome of young adults with epilepsy in childhood
}

\author{
Jorma Kokkonen, Eeva-Riitta Kokkonen, Anna-Liisa Saukkonen, Pirjo Pennanen
}

\begin{abstract}
Objective-To evaluate social maturation and psychiatric morbidity in young adults treated for epilepsy during their childhood.

Methods-Eighty one young adults (43 women, 38 men, mean age $22 \cdot 3$ years) with epilepsy during their childhood were interviewed about their social development and psychiatric symptoms. The results were compared with those from 211 randomly selected controls (106 women, 105 men, mean age $23 \cdot 2$ years).

Results-Compared with the controls the patients had more often not succeeded in passing the normal comprehensive school $(20 \% v 2 \%)$ or had left school at the secondary level $(53 \% v 46 \%)$ and remained without any vocational education $(27 \% v$ $11 \%)$. There was no significant difference in the employment status of those with work between the patients and the controls. The patients were significantly more often labelled with poor social maturation and dependent lifestyle factors such as living with their parents. However, risk analysis showed that neither the disease itself nor antiepileptic medication were significant predisposing factors for poor social adjustment but low or borderline mental capacity or learning disabilities relating to epilepsy were. Psychiatric morbidity was similar in both groups. Conclusions-The social handicap found in a certain group of young adults with epilepsy during childhood is largely associated with neurological and cognitive impairments other than epilepsy itself. With the present mode of treatment epilepsy itself does not seem to disturb adolescent social and psychological development.
\end{abstract}

Department of

Paediatrics

J Kokkonen

A-L Saukkonen

Department of Child

Psychiatry, University of Oulu, 90220 Oulu, Finland

E-R Kokkonen

P Pennanen

Correspondence to:

Dr Jorma Kokkonen

Department of Pediatrics,

University Hospital

FIN90220 Oulu, Finland.

Received 22 April 1996 and in final revised form 5 November 1996

Accepted 8 November 1996 disease affected social life considerably. According to Lindsay et $a l^{6}$ a third of young adults with temporal lobe epilepsy in their childhood were socially and economically dependent on their parents.

Epilepsy is still a disease which arouses complex attitudes among parents, peers, and teachers. ${ }^{78}$ Although the public attitude has been changing favourably and general knowledge about epilepsy among people has been increasing, it is not easy for a young epileptic person to see that this is so. Patients with epilepsy are overprotected by their parents more easily than non-epileptic patients and the patients themselves may think that they are different from their healthy peers. Separation from the parents in adolescence may therefore be complicated and delayed. This deviation in social relations may also be influenced by emotional trauma. ${ }^{9}$

To find out whether the disease is still unfavourably implicated in the social maturation of adolescents and young adults with epilepsy during their childhood, we re-examined and evaluated the social growth of an epidemiologically selected series of patient groups and compared the results with age matched controls.

\section{Methods}

PATIENTS AND STUDY DESIGN

The series comprised all the non-institutionalised patients with epilepsy born between 1964 and 1967 in the area of Oulu University Central Hospital, a total population of 250000 . From the 92 patients selected, 70 attended a re-examination in the outpatient clinics and another 11 responded to a questionnaire. As judged from the social status of the parents, the type of epilepsy, and school success, those responding by mail were identical to the attendees. Thus the total series comprised 81 young adults (43 women and 38 men, average age 22.3 (SD 1.9), range 19-24 years).

Generalised epilepsies as designated by the present international classification ${ }^{10}$ and determined from the history notes and EEG findings formed the biggest group, being found in 46 patients (idiopathic in 36 , cryptogenic in three, symptomatic with non-specific aetiology in four, and due to neurological diseases in three). Localisation related epilepsies were found in 35 patients (cryptogenic in 23, symptomatic in 11, and idiopathic in one). One fifth of the patients had begun to experience symptoms before 2 years of age and $40 \%$ 
before school age. At the time of the study 41 $(51 \%)$ of the patients were not taking medicine. One third (33\%) of the patients had not tried to stop taking antiepileptic medicine. As 13 of the remaining 54 had restarted, at the time of the study $40(49 \%)$ continued to take medicine. Twenty two patients used one medicine, 11 two, and seven three or more. Carbamazepine was the most common anticonvulsant - used for 28 patients-then dihydantoin for 17 , sodium valproate for 10 , and other types of drugs for seven patients. The medical outcome had been best in subjects with generalised idiopathic seizures. Only 5\% of all patients had had attacks during the year before the examinations. In the clinical examination a major neurological abnormality was found in three patients and mild motor abnormalities in four.

The control group for the sociodemographic data of the study was formed from a random sampling of a population cohort born between 1964 and 1967. The 211 (58\%) controls were selected from 358 who responded to the invitation letter (106 women, 105 men, average age 23.2 (SD 1.4), range 19-25 years). Only the 123 attending the interview personally were examined for psychiatric symptoms. The rest were interviewed for sociodemographic data by post.

\section{INTERVIEWS}

The social situation interview covered the Finnish comprehensive school and the vocational or higher education of each patient in detail. In Finland children enter school at 7 years of age and all complete six primary and three secondary classes. If the child has obvious developmental delay or has difficulties in following in class he or she will be tested for learning disabilities. Those with such difficulties are transferred to special classes (called auxiliary schools) and all are provided with an individually planned programme. After secondary school pupils have to decide whether they will proceed to senior high school or vocational education, after which most continue to midlevel vocational education or attend university.

Social descriptors considered to be important variables in social development (for example, employment status, independence from original family, and sexual relationships) were also covered in the questionnaire. The indices of social development were drawn from the physical indices or developmental stages com-

Table 1 The highest attained level of basic and vocational education of young adults with epilepsy in childhood and in controls

\begin{tabular}{llc}
\hline & $\begin{array}{l}\text { Patients }(n=81) \\
n(\%)\end{array}$ & $\begin{array}{l}\text { Controls }(n=211) \\
n(\%)\end{array}$ \\
\hline $\begin{array}{l}\text { Basic education: } \\
\quad \text { None or auxiliary school }\end{array}$ & $17(20)$ & $4(2)$ \\
$\begin{array}{l}\text { Comprehensive school } \\
\text { High school }\end{array}$ & $42(53)$ & $97(47)$ \\
$\begin{array}{l}\text { Vocational training and } \\
\text { further education: }\end{array}$ & $22(27)$ & $110(51)$ \\
$\quad$ None & & \\
$\quad$ Basic & $22(27)$ & $24(11)$ \\
Advanced/university & $41(50)$ & $120(57)$ \\
\end{tabular}

${ }^{\star} \chi^{2}=38.2, \mathrm{P}<0.001 ;+\chi^{2}=11.5, \mathrm{P}<0.01$ pleted. Separation from parents for instance, was evaluated from such facts as living away from home, economic self reliance, and managing their own affairs. The index of social maturation was used to describe development towards achieving independent life as an adult. It was formed by scoring five social descriptors (studying/vocational education, employment, separation from parents, marital/sexual relationships, and economic independence) on a scale from 1 to $4(1=$ ready/achieving, $2=$ ongoing, realistic, $3=$ idea, no practical steps, $4=$ missing, disorganised). ${ }^{11}$ The index was evaluated only for those interviewed personally.

The method of psychiatric case identification used was a short version of the present state examination (PSE) interview analysed by a Catego program. Since originally developed and described by Wing, ${ }^{12}$ this has been used in several epidemiological studies and its reliability is well documented. ${ }^{13-15}$ The procedure provides a set of rules for deciding the "caseness" of the case, the choice being made primarily from clinical experience. The susceptibility to have a disorder is indicated by an index of definition (ID) with five considered as a cut-off point.

\section{STATISTICAL METHODS}

Statistical analysis was performed with the SAS program (CATMOD, FREQ, GLM, MEANS procedures). The cases and controls were compared by a $\chi^{2}$ test for categorical data and a $t$ test for continuous data and $95 \%$ confidence intervals (95\% CIs) are given when appropriate. Both multivariate and univariate logistic regression analysis were used to analyse the associations between the social maturation index and various demographic or disease related variables. As the two analyses produced practically the same results we report only the relative risk ratios and their 95\% CIs produced with univariate analysis.

\section{Results}

\section{SOCIAL OUTCOME}

Seventeen $(20 \%)$ of the patients in the study group had been unable to complete the normal elementary school course of nine years, whereas only four of the controls failed to do so (table 1). These were considered as a learning disabled group. A quarter (27\%) did complete high school. The figure was nearly twice as high among the controls.

About half of each group had selected vocational education and training after the third year of secondary school or high school. The patients had selected commercial fields twice as often as the controls. Finally, up to 27 (95\% CI $21-43) \%$ of the patients and $11(95 \% \mathrm{CI}$ $4-15) \%$ of the controls failed to complete professional education or were left wholly without it. One fifth of each group continued to midlevel vocational education or university.

State welfare benefits were the main source of income for 10 patients $(12 \%)$ in the study group and for four controls (2\%). Three other patients had been able to stop the pension which had started after comprehensive school, 
Table 2 Present employed status of young adults with epilepsy in childhood and in controls

\begin{tabular}{llc}
\hline & $\begin{array}{c}\text { Patients }(n=81) \\
n(\%)\end{array}$ & $\begin{array}{l}\text { Controls }(n=211) \\
n(\%)\end{array}$ \\
\hline On disability pension & $10(12)$ & $4(2)$ \\
Students & $20(26)$ & $70(33)$ \\
Employed: & $51(62)$ & $137(65)$ \\
Permanently & 18 & 71 \\
Temporarily & 22 & 47 \\
Unemployed & 8 & 11 \\
Other & 3 & 8 \\
\hline
\end{tabular}

$\chi^{2}=14 \cdot 7 ; \mathrm{P}<0 \cdot 001$. with other types. Continuing medical treatment was not a significant factor in disturbing social development.

\section{MENTAL DISORDERS}

The overall prevalence of mental disorders as defined by PSE criteria for a psychiatric "case" (ID $\geqslant 5$ ) was 18 (95\% CI 9-27)\% among the epileptic patients and $22 \%(95 \%$ CI $11-25) \%$ among the controls. The CATEGO program identified non-specific or single key symptoms as identified by ID $3-4$ in roughly a third of each group.

Depressive (ICD-9 code $296 \cdot 2$ or $300 \cdot 4$ ) and had joined the labour force. As one fourth of the study group and one third of the controls continued their studies, the remaining 51 $(63 \%)$ of the patients and $137(65 \%)$ of the controls formed the actual labour force. Table 2 shows their present and previous state of employment as well as their experience of unemployment, indicating that more than twice the percentage of patients in the study group were unemployed than controls. The range of working fields or employers were not significantly different between the groups. Patients with epilepsy were not more likely to work in the public services than the controls.

SOCIAL MATURATION

The patients in the study group were significantly more often unmarried and not cohabiting than the controls (table 3). They also continued to live with their parents more often.

Up to $30 \%$ of the patient group were considered to have a delayed social maturation towards adulthood. The figure for the controls was $17 \%\left(\chi^{2}=4.95, \mathrm{P}<0.05\right)$.

When analysed for patients and controls together, impaired intellectual capacity and learning disabilities were the most significant risk factors (table 4). Epilepsy in itself (for example, to be taking or to have taken antiepileptic medication) did not predispose patients to poor social maturation. Patients in the study group with a localisation related type of epilepsy did significantly better than those

Table 3 Marital and living status of young adults with epilepsy in childhood and in controls

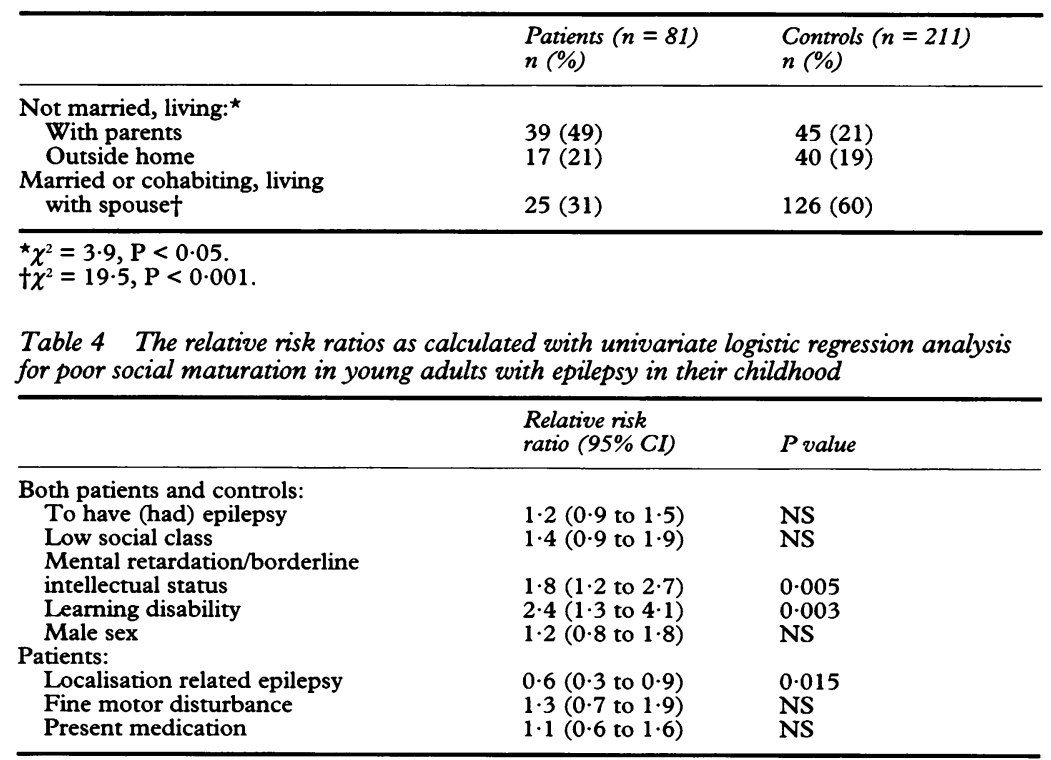

syndromes were identified in six $(10 \%)$ patients and five (8\%) controls and anxiety (codes $300 \cdot 1$ and $300 \cdot 2$ ) syndromes in 13 (11\%) patients and $14(12 \%)$ controls respectively.

\section{Discussion}

The main object of this study was to discover how young people with epilepsy during their childhood grow out of their puberty and succeed in managing social life (vocational training and employment, sexual development, choosing a lifestyle, and career) in early adulthood and whether psychiatric morbidity excessively complicates this developmental cascade. As the youngest of the subjects were at least 19 years of age and pubertal this aim was reliably achieved. A special merit of this study compared with the wide ranging literature published on this subject, was the control group selected at random from the same area and investigated extensively by the same methods. The breakdown of different types of epilepsy also matched previous studies closely. Idiopathic or cryptogenic generalised and localisation related epilepsies formed the main body $(78 \%)$ of all cases.

The main finding from the aspect of social development was that children with juvenile onset epilepsy become preselected with a subgroup of subjects with low intelligence and learning disability. These factors were found as the main risks for poor social maturation. Learning disability influences social maturation through school success, vocational education, and how a young person handles the relationship with parents. The physical disease itself or taking medication for it did not significantly affect social development.

Although vocational education was retarded in a third of epileptic patients, a figure three times greater than among the controls, two thirds had been proceeding in their educational career after secondary school without any great difficulties. In a closer risk factor analysis, epilepsy with good response to treatment was no additional risk in preventing completion of vocational education or joining the labour force. The main risks of remaining without gainful vocational education were again low or borderline intellectual capacity, lack of success at school, and intractable disease, these three being strongly correlated. On the other hand even among the controls $10 \%$ did not gain educational skills for their future work period. 
Only two of the patients were disabled enough by the disease to have a disability pension. Eight others had it mainly for restricted mental capacity.

The Finnish welfare and social allowance system was inefficient in supporting the social maturation process in terms of separation from parents and developing a self reliant lifestyle. Judging by their physical and mental capacity, more of the young people could have been trained to work at least half time or in sheltered workshops to provide some satisfaction and motivation in their lives.

A home based lifestyle was seen as deviant social maturation. As stated above this was strongly associated with the educational and vocational career after secondary school, but even subjects with normal mental capacity and idiopathic disease were more tied to their parents and home, lived at home more often, and had retarded sexual maturation compared with the controls. The results in this respect may reflect the earlier findings that children and adolescents with long term diseases are overprotected in the family. The parents and the patients seem easily to form a mutually dependent style of living. This was specially true if the patient had one or more related handicaps or functional disability.

Studied by a short version of PSE, our results showed an equal number of mental disorders in patients and in controls. The experience of psychosomatic symptoms was also equal during the last year, confirming the main result of equivalent incidence of mental problems. Our conclusion therefore is that in the long run patients with epilepsy in childhood are no more prone to manifest overt psychiatric disorders later in life. This finding is not in agreement with the general assumption, that children with epilepsy are considered to have more psychological problems than controls. ${ }^{16}$ This conclusion applies more so to adolescents, but this view is mostly based on selected patients not followed up until adulthood. One possible explanation for this discrepancy and the apparently decreasing tendency to psychological problems is that some of the mental disorders really do remit during adolescence for the "second chance" described by Laufer. ${ }^{17}$

We conclude that patients with epilepsy during childhood have retarded social growth into adulthood more often than controls, appearing as a more parent based living style and lack of gainful vocational education. These deviations seemed to be more influenced by preselection of the epileptic population than by the disease itself. The fact that a patient is using or has previously been using antiepileptic drugs seems to have minimal or no social consequences. Another important conclusion was that evaluation and handling of the developmental questions in adolescence should be a part of the treatment of epilepsy so that this kind of social deviation could be avoided as far as possible. This goal is best achieved in special units working between the paediatric and adult healthcare system.

This study was supported by a grant from Gyllenberg Foundation, Helsinki, Finland.

1 Bagley C. Social prejudice and the adjustment of people with epilepsy. Epilepsia 1972;13:33-45.

2 Camfield C, Camfield P, Smith B, et al. Outcome of childhood epilepsy: a population based study with a simple predictive scoring system for those treated with medication. 7 Pediatr 1993;122:861-8.

3 Sander J. Some aspects of prognosis in the epilepsies: a review. Epilepsia 1993;34:1007-16.

4 Sillanpää $M$. Children with epilepsy as adults. Outcome after 30 years of follow-up. Acta Paediatr Scand 1990; after 30 years of

5 Sillanpää $M$. Remission of seizures and predictors of intractability in long-term follow-up. Epilepsia 1993;34: 930-6.

6 Lindsay J, Ounsted C, Richards P. Long-term outcome in children with temporal lobe epilepsy. Social outcome and childhood factors. Dev Med Child Neurol 1979;21: 285-98.

7 Caveness W, Gallup G Jr. A survey of public attitudes toward epilepsy in 1979 with an indication of trends over the past 30 years. Epilepsia 1980;21:429-518.

8 Jensen R, Dam M. Public attitudes toward epilepsy in Denmark. Epilepsia 1992;33:459-61.

9 Ounstedt C, Lindsay J. The long-term outcome of temporal lobe epilepsy in childhood In: Reynolds E, Trimble M, eds. Epilepsy and psychiatry. Edinburgh: Churchill eds. Epilepsy and psychia

10 Manford M, Hart Y, Sander J, et al. The national general practice. Study of epilepsy. The syndromic classification of the international league against epilepsy applied to epilepsy in a general population. Arch Neurol 1992;49. 801-8.

11 McAnarney E. Social maturation. A challenge for handicapped and chronically ill adolescents. $\mathcal{F}$ Adolesc Health Care 1985;6:90-101.

12 Wing J, Cooper J, Sartorius N. Measurement and classification of psychiatric symptoms. Cambridge: Cambridge University Press, 1974.

13 Lehtinen V, Lindholm T, Veijola J, et al. The prevalence of PSE-CATEGO disorders in a Finnish adult population cohort. Soc Psychiatr Epidemiol 1990;25:187-92.

14 Kokkonen J, Kokkonen ER. Prevalence of mental disorders in young adults with chronic physical diseases since in young adults with chronic physical diseases since childhood as identified by the present state examination and the CAT 239 .

15 Rodgers B, Mann S. Reliability and validity of PSE, assessments by lay interviewers; a national population survey Psychol Med 1986;16:689-90.

16 Goodman R. Brain disorders. Epilepsy. In: Rutter M Taylor E, Hersov L, eds. Clinical and adolescent psychiatry. Modern approach. Oxford, Blackwell Scientific Publications, 1994:182-4.

17 Laufer M. Adolescent disturbance and breakdown. London Pelican Books Mind Specials, 1975. 